\title{
THE MERITS OF QUIZLET FOR VOCABULARY LEARNING AT TERTIARY LEVEL
}

\author{
Agung Ginanjar Anjaniputra \\ English Education Study Program, Universitas Suryakancana, Cianjur, West Java \\ E-mail: anjaniputragi@gmail.com \\ Vina Aini Salsabila \\ English Education Study Program, Universitas Suryakancana, Cianjur, West Java \\ E-mail: vnsabila91@gmail.com
}

APA Citation: Anjaniputra, A. G., \& Salsabila, V. A. (2018). The merits of Quizlet for vocabulary learning at tertiary level. Indonesian EFL Journal, 4(2), 1-11. doi: 10.25134/ieflj.v4i2.1370.

Received: 12-03-2018

Accepted: $28-05-2018$

Published: 01-07-2018

\begin{abstract}
Vocabulary has been at the pinnacle of language learning since vocabulary mastery helps in communicating language. However, learning vocabulary yields problems prevalent among learners of this new digital era such as low participation and difficulties to keep learners attentive to lessons being learned. Deploying classroom action research, this study aims to depict the implementation of Quizlet in learning vocabulary at the tertiary level and to elicit learners' responses to Quizlet utilization in the classroom. In this regard, observation and interview were triangulated to get an enhanced portrayal of what occurred during the learning. These instruments resulted in findings that Quizlet to some extent helped in fostering learners' engagement, as well as persistence in vocabulary learning and that the learners enjoyed learning vocabulary in Quizlet and considered Quizlet as useful and beneficial tool for their learning development, particularly in vocabulary learning. Hence, it is suggested that teachers make use of Quizlet to provide learners with a new way of learning that is interesting, innovative, and probably improving learners' learning experiences, eventually fulfilling the learners' demand of the $21^{\text {st }}$ century.

Keywords: Vocabulary learning; Quizlet; learner engagement; CALL.
\end{abstract}

\section{INTRODUCTION}

Vocabulary is inextricably linked to the production and comprehension of language. Insufficient vocabulary may limit one to understand and produce speech as well as text. In line with it, Groot (2000) affirms that vocabulary has something to do with reading, listening, speaking, and writing. As an example, a person must at least master 5000 words to be able to comprehend nonspecialized texts (Nation, 1990) cited in (Groot, 2000). Despite its primacy of vocabulary these days, many students have limited numbers of vocabulary (Barr, 2016), which can prevent them from producing and understanding a large coverage of speech or text. Moreover, so long as vocabulary learning is concerned, problems of learning vocabulary are apparent among second language learners (Gass \& Selinker, 2008). In this regard, based on the writers' experience, students are also indifferent to the learning, leading to reluctance to participate. Besides, the students seem to be unenthusiastic about and inattentive to it. Therefore, vocabulary needs are learned an interesting way.

One interesting way of learning vocabulary is by incorporating technology into the classroom, known as Computer Assisted Language Learning, henceforth CALL. It will not bring about any significant technical problems since technology is now indispensable and students live with it. Roles of CALL in vocabulary learning are crucial since it provides students with metacognitive activities allowing for making inferences through contexts using imagery and semantic techniques (Kose, Cimen, \& Mede, 2016). It is affirmed that the use of technology in the classroom is, in fact, beneficial in a way that it can motivate students and engage them in 
learning (Wieking, 2016). Besides, the development of technology allows language teachers to easily make use of it.

Technology, as Vargas (2011) argues that it can be realized through CALL, promotes persistence in reading lessons. It constitutes supplementary classroom activities which can motivate students to engage in learning activities. Once students are engaged, they may willingly explore their interests so that students can learn at their own pace, allowing for self-control over the learning. Twyman \& Tindall (2006, cited in Vargas, 2011) assert that the ability to make the learning personal brings about more involvement and success feeling that are likely to stimulate students to motivate themselves in continual learning.

One of the realizations of CALL recently prevailing, especially for vocabulary learning, is by using Quizlet that is a new sophisticated tool specifically designed for learning vocabulary. Found in 2005, it comes with an array of features that can help teachers to organize their classes. It promotes collaborative learning, drilling, and repetition, as well as enjoyable fun ways of learning. Therefore, students are not bored easily.

Quizlet has been researched to measure its significance for vocabulary learning. Research on Quizlet was conducted to see its effect on vocabulary learning (see Vargas, 2011; Ashcroft \& Imrie, 2014; Barr, 2016; Kálecký, 2016; Andarab, 2017), and to explore EFL learners' views on the use of Quizlet (Lander, 2016; Kose, Cimen, \& Mede, 2016). Despite a few studies concerning Quizlet, research descriptively qualitative investigation of Quizlet at tertiary level, which is particularly combined to search for the students' responses, is lacking. This gap is necessary to be filled since it can enrich knowledge of using a digital-based tool for vocabulary learning in Indonesia. Furthermore, the issue of technology integration in the classroom is prevailing and attracting many scholars.

Quizlet is a website that allows users to learn vocabulary by means of flashcard sets using a variety of game-like learning tools. It is also available for Android and iOS, allowing users to use it anytime and anywhere. For the teacher, classes may be created to manage certain students learning with certain lexical items. The flashcard sets are easily free for all Quizlet users to create, dependent on vocabulary to learn. Learners can also contribute to sets created by teachers or make their own vocabulary sets for learning. The sets consist of terms for the lexical items and definitions for the description where a picture or sound can be added.

The game-like tools comprise two main categories: Study and Play. In Study, there are five modes entailing Learn, Flashcards, Write, Spell, and Test; "Learn" allows users to take control of their learning to get them familiar with the sets; "Flashcards" as its name implies provides users with digital flashcards that can be flipped over by only clicking on the card; "Write" is to write the correct term of the description shown; "Spell" provides users with spelling practice in which listening to the spelling and writing the correct answer of the spelling are encouraged; "Test" is indeed designed for testing purposes, whose users are given random questions based upon the given set and results are directly shown as all the questions are answered. In the meantime, three choices are available in Play, encompassing Match, Gravity, and Live; "Match" allows users to match terms and definitions scattered around the screen; "Gravity" presents meteors with words on it, then users have to type the answer for the words before the meteors hit the earth; "Live" is an online collaborative activity where each group competes to reach certain criterion by answering correctly because one wrong answer will cause the group to start from the beginning. All of the modes can be monitored by the teacher as long as students are included in the created class. For instance, whether or not students have completed Study modes can be seen or items answered by students are shown statistically, allowing for revising or focusing on items answered correctly or incorrectly most of the time by students.

Quizlet has been reported to have some virtues as well as shortcomings in its implementation. It gives advantages in terms of learners' performance, engagement, autonomy, interests, and motivation. The advantages of it result from some studies 
suggesting that commonly students can progress if learning by using Quizlet (Vargas, 2011; Ashcroft \& Imrie, 2014; Kálecký, 2016; Andarab, 2017), particularly kinesthetic learners can generally perform well for testing (Barr, 2016); learners' engagement in the classroom is apparent (Vargas, 2011; Barr, 2016; Beyer \& Lynch, n.d.); it results in learners' autonomy to learn on their computers and smartphones (Vargas, 2011; Barr, 2016; Kálecký, 2016; Beyer \& Lynch, n.d.); a new, enjoyable way of vocabulary learning is provided (Lander, 2016; Beyer \& Lynch, n.d.); students can control their progress and directly see at which part of vocabulary sets the students to lack (Kálecký, 2016); and students can benefit from the "spell section" to improve the spelling of words (Vargas, 2011; Kálecký, 2016).

Notwithstanding the aforementioned advantages, a number of barriers also occur. The barriers encompass the failure to encourage spaced repetition (Barr, 2016), students' negligence of sets whose unit tests were completed (Barr, 2016), a heavy workload on students' mind (Beyer \& Lynch, n.d.), social distraction so long as phones are used (Beyer \& Lynch, n.d.), and the internet connection, phone memory, low-charged battery, and acceptance of only the exact same answers (Kálecký, 2016). It is worth noting that teachers who are interested in implementing Quizlet should anticipate the possible drawbacks.

These disadvantages are however challenged to the implementation of CALL, Quizlet in particular. In this case, learner autonomy, which may result from using
Quizlet, plays a vital role to deal with those shortcomings. According to Nation (2001), responsibility for learning is typical of autonomous learners, who are also capable of taking control of their own learning. Hence, it is expected that once autonomy is attained, the problems of spaced repetition failure, negligence, social distraction, etc. mean nothing as autonomous learners are aware of deciding when, where, what, which, how much certain items should be learned.

Puentedura (2006, cited in Ashcroft \& Imrie, 2014) proposed a model to assess the integration of technology into the classroom, the so-called the SAMR model. It is the abbreviation of the Substitution Augmentation Modification Redefinition Model. The SAMR model is recommended for English language teaching contexts in which Learning is particularly deployed (Hockly, 2013, cited (Romrell, Kidder, \& Wood, 2014). This model, as suggested by Puentedura (2006, 2010), classifies four stages that can progressively impact on the learning activities in the classroom. Substitution is when technology is used to replace old-fashioned ways of learning, yet the function is still the same. Meanwhile, augmentation deals with replacing tasks with some improved functions. Besides, modification allows for redesigning tasks in a significant way. The last is Redefinition in which new tasks previously inconceivable are created by technology. The four stages are also depicted in Table 1, comprising the definitions and examples of Quizlet application by Ashcroft and Imrie (2014, p. 641).

Table 1. The SAMR model for technology impact assessment

\begin{tabular}{lll}
\hline Substitution & $\begin{array}{l}\text { Technology is used to perform } \\
\text { the same kind of task that was } \\
\text { done before computers }\end{array}$ & e.g., making basic digital flashcards \\
\hline Augmentation & $\begin{array}{l}\text { Although still acting as a substitute, } \\
\text { technology offers some functional } \\
\text { improvement }\end{array}$ & $\begin{array}{l}\text { e.g., making digital flashcards } \\
\text { with images and audio }\end{array}$ \\
\hline Modification & $\begin{array}{l}\text { Technology facilitates significant task } \\
\text { redesign }\end{array}$ & $\begin{array}{l}\text { e.g., generating a test from a set of } \\
\text { digital flashcards }\end{array}$ \\
\hline Redefinition & $\begin{array}{l}\text { Technology allows for the creation of } \\
\text { tasks that were previously } \\
\text { inconceivable }\end{array}$ & $\begin{array}{l}\text { e.g., inter-class/inter- } \\
\text { school/international digital } \\
\text { flashcard learner collaboration }\end{array}$ \\
\hline
\end{tabular}


In detail, (Ashcroft \& Imrie, 2014) further exemplify the activities representing each stage of the model. Substitution has to do with making digital flashcards as a study set. Besides, Augmentation entails combining the flashcards with pictures or sounds, and studying in modes available, mobile Quizlet, and printing. in addition, Modification encompasses importing data for creating the study set, using the Test mode, and sharing a set through the website. Lastly, Redefinition comprises studying together or sharing resources, which puts emphasis on student collaboration such as using the Live mode.

In addition to the SAMR model, the way vocabulary should be taught entails some considerations in order that learning and acquisition can occur. The first one is the concreteness of vocabulary presented to students. It is found that concrete and cognates words are learned more easily compared to the abstract and noncognate ones (Groot \& Keijzer, 2000). This to a certain extent supports the notion of Transfer where similarities in terms of vocabulary in the first language can ease learners' acquisition of words in the second language (Steinberg \& Sciarini, 2006). In addition to cognate and concrete vocabulary, Nation and Macalister (2010) propose that high-frequency words should be prioritized. This means that words required to be acquired in advance are those mostly used in communication. However, lowfrequency vocabulary can be taught as long as the high-frequency items have been covered. It is further argued that regardless of high and low-frequency lexical items, academic vocabulary cannot be neglected (Nation, 2001). It is important, in spite of uncommon occurrence in non-academic texts, because of its substantial number of words in academic texts (ibid.). In the tertiary level, academic texts constitute common materials for students in the four language skills. Thus, academic words should be taught to learners at the tertiary level of education.

Unlike adult learners, for children, as they are in the critical period, it is easy to acquire a huge number of words by means of induction through high exposure to the use of words. According to Steinberg and Sciarini (2006), as people reach adulthood, their memory ability declines. This implies that to acquire certain vocabulary, adult learners need not only high exposure but also drilling and repetition. This is suggested by Schmidt (2008) that maximized exposure and incidental learning, as well as explicit intentional learning, are components required for vocabulary learning programs. Vocabulary learning through explicit learning is said to be effective, which leads to long retention. In addition to this, Nation and Macalister (2010) that repetition is necessary for a language program. It is stated that language-focused learning, one of which is vocabulary, should be taught to students through, as further exemplified, repetition or vocabulary learning on cards. Repetition and flash cards are typical of learning vocabulary in Quizlet, yet in different forms which are online and digital-based.

With regard to previous related studies and literature review of vocabulary learning, the process of vocabulary learning by implementing Quizlet is very much of concern. Therefore, this study is aimed at depicting how the use of Quizlet in the classroom is for learning vocabulary, and how students at the Tertiary Level respond to the use of Quizlet.

\section{METHOD}

Deploying classroom action research, this study focused on qualitative means of describing the data. In this regard, the data were portrayed descriptively in relation to what really occurred in the classroom while Quizlet was implemented. The participants constituted a class of the fourth year students taking the Complex Vocabulary Subject, which consisted of 30 students. Yet, not all the students were involved since some of the students missed the class as Quizlet was applied. Through classroom observation, tests and interview, data were collected in this study. Classroom observation and tests were intended to yield the merits of using Quizlet in the classroom, especially for vocabulary learning. In the meantime, the interview was administered to elicit the student's responses on the use of Quizlet and, to a certain extent, 
to confirm what was found in the classroom observation so the data were triangulated.

The implementation of Quizlet was divided into four meetings. The first one was when Quizlet was solely used in the classroom and the students were able to learn based on their own preferences. Students started to get accustomed to learning by means of Quizlet. the items learned in this meeting were synonymous words such as nil and naught, shallow and superficial, etc. Likewise, the second meeting was also carried out to have students learn antonymous words prepared in a study set, for example, bring about vs avert, Persistent vs loath, etc.. The third meeting was somewhat different from the previous meetings that the students focus on the Test mode to pass the criteria set by the teacher. The items learned are, for instance, in/with regard to, remind about/of, etc.. The fourth meeting differed from the third meeting in terms of the learning activities which focus on the Game modes. The vocabulary learned was verbs such as a stop to do/doing and have something done/do distinctions. The activities comprised guessing games, writing exercises, the whisper game, and completing exercises. Vocabulary learned in the meetings entailed selected words, many of which are advanced words marked " $\mathrm{A}$ " in Cambridge Advanced Learners' Dictionary, $3^{\text {rd }}$ edition.

Prior to coming to the class, the teacher created a class so that students could join and provided a vocabulary set linked to the class. The students were given a class link to join the class and the students clicked on or followed the link would be directed to the class. After clicking "join", the teacher will accept the students. Once the students joined the class, access to the prepared set including Study and Play modes are open. Therefore, before coming to the class, most of the students had joined the class. In the next meeting, since all students joined the class, what was prepared was another vocabulary set so, in advance of the class meeting, the set had been ready and linked to the class. In the classroom, everything was ready for students to use Quizlet. During the classes, all student activities were videotaped for the sake of data analysis. After the fourth meeting, a test was administered to get a description of students' attainment.

The data were then analyzed by means of describing the activities in the classroom and how the students did the activities. To result in the findings, the data from the observation and the interview were coded to generate broader themes. The themes were categorized based on several recurring patterns of the students in relation to how the students react to the use of Quizlet in the classroom. The themes of the classroom observation were compared to the resulted themes of the interview to confirm the findings. The themes prevailing in both the data of classroom observation and the interview are to be analyzed for interpretation. The findings resulted in the portrayal of how the deployment of Quizlet in the classroom was for vocabulary learning. In addition to the analysis of the observation and the interview, an analysis to yield students' responses to the use of Quizlet was carried out, whose data are of the interview result. The result of the analysis bore the students' responses. Similarly, these findings were also interpreted to come up with a thoroughly comprehensive understanding of issues under investigation.

\section{RESULTS AND DISCUSSION}

This section presents findings of how the use of Quizlet in the classroom is for vocabulary learning and how students respond to the use of it. The use of Quizlet in the classroom is going to be presented separately in each meeting so there will be four meetings portrayed accordingly. This finding will consecutively be discussed and supported by the data from the interview. Concerning the students' responses, the results are conveyed descriptively.

\section{The implementation of quizlet}

In general, to follow the SAMR model, the use of Quizlet in the classroom realized the three stages: Substitution, Augmentation, and Modification. The substitution was realized through making flashcards in Quizlet; Augmentation was manifested in a variety of modes where the digital flashcards were combined with the spelling-sound; modification was demonstrated when students 
were provided with test generated randomly from the given set in the "Test" mode. The whole depiction of Quizlet integration in the classroom is shown in Table 2. The details of what occurred and of students' activities in the classrooms are also portrayed in each meeting, following the table.

Table 2. The integration of Quizlet

\begin{tabular}{|c|c|c|c|c|c|}
\hline \multirow[t]{2}{*}{ Phases } & \multirow[t]{2}{*}{ Meeting 1} & \multicolumn{4}{|c|}{ Meeting } \\
\hline & & 1 & 2 & 3 & 4 \\
\hline Substitution & Making flashcards of a study set & $\sqrt{ }$ & $\sqrt{ }$ & $\sqrt{ }$ & $\sqrt{ }$ \\
\hline \multirow[t]{5}{*}{ Augmentation } & Studying in Flashcards mode & & $\sqrt{ }$ & $\sqrt{ }$ & \\
\hline & Studying in Spell mode & & $\sqrt{ }$ & $\sqrt{ }$ & \\
\hline & Studying in Learn mode & & $\sqrt{ }$ & $\sqrt{ }$ & \\
\hline & Studying in Write mode & & $\sqrt{ }$ & $\sqrt{ }$ & \\
\hline & Studying in the Game mode & $\sqrt{ }$ & $\sqrt{ }$ & $\sqrt{ }$ & $\sqrt{ }$ \\
\hline \multirow[t]{4}{*}{ Modification } & Modifying flashcards imported from other sources & & $\sqrt{ }$ & $\sqrt{ }$ & $\sqrt{ }$ \\
\hline & Using the Test mode & $\sqrt{ }$ & $\sqrt{ }$ & $\sqrt{ }$ & \\
\hline & Creating a class & $\sqrt{ }$ & $\sqrt{ }$ & $\sqrt{ }$ & $\sqrt{ }$ \\
\hline & Monitoring progress & & $\sqrt{ }$ & $\sqrt{ }$ & \\
\hline
\end{tabular}

\section{Meeting 1}

The class began with checking the attendance list. After that, the teacher asked the students about joining the Quizlet class as it had been told beforehand. However, there were some students had not joined the class for some reasons such as the limited internet connection, problems in logging in because of forgetting the email registered as well as the password losing the class link, and negligence as the students had missed the previous class. The teacher asked the students to go on joining the class, while other students who had joined the class were asked to exploring Quizlet by learning the set for that meeting which was about synonymous words. Besides, another problem was that some students did not bring laptops as they had been told. Laptops were used since some features could not be accessed by some smartphones, such as "Gravity" and "Live". So to handle this problem, the teacher allowed students to use their smartphones.

To attract students' attention to Quizlet, the teacher asked the students to play "Match" or "Gravity". This was intended to motivate students to learn vocabulary as if they were playing a game. Learning is better if students can enjoy it, which in turn can engage them and increase their interests in learning. This is in accordance with (Vargas, 2011) that making students engaged in learning, as one of the benefits of using technology, may lead to the exploration of their interests so that students can learn at their own pace, allowing for selfcontrol over the learning.

When students were playing Gravity or Match, the teacher informed students that their scores would be recorded automatically. Match recorded students score in terms of seconds or minutes, the faster students complete the task, the higher their ranking is. Meanwhile, gravity recorded the score from nil to hundreds, thousands, tens of thousands, or even hundreds of thousands depending on how long users can last. They seemed enthusiastic to get the highest score so that their names could be shown in the top three ranking. It was observed that once a student got the first rank, then being replaced by her friend, the student tried to get her position back on to the top. It indicates that Quizlet encourages students to be motivated and engaged in the learning. This was also mentioned by the students in the interview that Quizlet made them engaged in learning. Thus, this finding is in harmony with some previous studies that learners' engagement in the classroom is apparent (Vargas, 2011; Barr, 2016; Beyer \& Lynch, n.d.).

\section{Meeting 2}

The vocabulary items learned were presented in antonymous pairs. The teacher asked the students to go to Match. Yet, some preferred accessing Learn, Spell, Write, Flashcards, or even just scrolling down the set. This shows that the students tried to control their own 
learning based on their own pace. This is an indication of autonomy possessed by the students at it is affirmed by Nation (2001) that autonomous learners are capable of taking control of their own learning. Moreover, the situation may be caused by the willingness of the learners to first learn what is required for them, instead of directly accessing Match. It seemed that the students internalized the learning in the previous meeting so that the students monitored their learning. This confirms the previous studies that Quizlet results in learners' autonomy to learn (Vargas, 2011; Barr, 2016; Kálecký, 2016; Beyer \& Lynch, n.d.).

It is worth noting that Match to some extent helps in increasing students' interests to learn, yet it brings about a problem. The problem was that the students match the flashcards as fast as they possibly could without reading the words at all. Remarkably, the students can complete a task in Match in only 7 seconds. This was because the scores shown in the ranking are the time to complete a task. Therefore, since the students wanted their names to be shown in the ranking list, they irresponsibly do so. At least, two ways can be done to prevent this. The first one is by creating a set which has the similar number of words in the term boxes and in the definition boxes. It is better to replace the definitions that comprise long sentences or phrases with pictures, if not by a single word as the term itself. The second way is by only allowing students to play in the hard level of difficulty, not the easy or medium one. In a hard level, so many flashcards are shown, limiting students to match without even reading it. If they do so, much time will be spent.

After playing in Match and Gravity, students were directed to Test. The test was deliberately focused on 20 written questions. Each student was given the 20 questions randomly and no one got the exact same questions. The students were challenged to get a score of 80 . Some students were surprised because they got bad marks. However, this initiated students' interests as they kept on doing it until they scored 80. A few students scored 80 easily, so they were asked to score 100. In contrast, it was harder for them to score 100, the students could not believe it. A student scored 90 several times and showed the scored to the teacher. Nevertheless, it did not stop the students re-trying on and on again. The student was persistence in scoring 100 no matter how hard it was. This evidence corresponds to the argument that the use of technology in the classroom is, in fact, beneficial in a way that it can motivate students and engage them in learning (Wieking, 2016).

\section{Meeting 3}

In the third meeting, the teacher directly asked students to learn the way the students want. Most of the students preferred Match to other modes. Some accessed Learn, Write, Flashcards, etc.. After 20 minutes of exploring Quizlet, the teacher asked students to access Test. Instead of answering 20 questions in Test of the previous meeting, the students were merely instructed to answer ten questions in each turn of Test. The type of questions allowed was still the written question. The students were allowed to move to the next stage of answering 20 questions in Test as the students scored perfectly for ten questions. Few students could pass this and started to answer 20 questions. When the students finished completing a test, their scores were mentioned to attract the teacher's attention. While mentioning their scores the students looked proud when the score was high but annoyed when the score was disappointing.

In addition, it was observed that after answering the test and the result was disappointing, the students return to the set to remind them about the answer. Sometimes, the students also jotted down something on their notebooks concerning the vocabulary items being learned. students can control their progress and directly see at which part of vocabulary sets the students to lack (Kálecký, 2016). Once the information the students required was found in the study set, the students started over the test. Failure in the test seemed to boost the students to strive harder. It was observed that the students relentlessly made any endeavor to pass the criteria set by the teacher. This showed that students' persistence was generated. Regarding this, the 
student interview also yields that Quizlet is deemed effective to promote students' persistence in vocabulary learning.

Albeit the prevailing student persistence, a number of problems were apparent in this meeting, including the internet connection which immediately was unreachable by their phone and mistyped answers. Several students were impeded by this mistyping problem. A student told the teacher that "I should have gotten a better score if I had not mistyped the answers". These problems were also found by (Kálecký, 2016). Besides, it is stated that phone memory and low-charged battery alongside the internet connection and mistyped answers were issues in using Quizlet. Concerning the mistyping problem, teachers must remind students to carefully type the answer.

\section{Meeting 4}

The students were previously asked to bring laptops to the class because the teacher intended to focus on Gravity. of other features in Quizlet, Gravity resembles a modern game designed not for learning. Thus, when playing Gravity, the students can enjoy the game. Games stimulate students to learn because students consciously play games, yet subconsciously learn vocabulary. Gravity is wrapped in such a way so students were interested in the game. This is consistent with the fact that Quizlet provides a new, enjoyable way of learning vocabulary (Lander, 2016; Beyer \& Lynch, n.d.). One of the features generates enjoyment, as mentioned before, is Gravity.

Gravity interests students in a way that the students can maintain their focus and attention. It is worth mentioning that as the time was up, a few students continued playing Quizlet. Their continual learning was also noted that there was a change in the top ranking of Match and Gravity after the class ended. This shows that the students personalized their own learning. Twyman \& Tindall (2006, cited in Vargas, 2011) assert that the ability to make the learning personal brings about more involvement and success feeling that are likely to stimulate students to motivate themselves in continual learning. The learning is continued and done repeatedly by certain students until the students became one of the top scorers. It is suggested by Nation \& Macalister (2010) that vocabulary should be taught to students through repetition or vocabulary learning on cards. Hence, repetition of vocabulary being learned can lead to long retention of the words.

After the fourth meeting, a test is carried out. The result is discernable in the table below.

Table 3. Students' scores

\begin{tabular}{crcrcr}
\hline Students & Scores & Students & Scores & Students & Scores \\
\hline 1 & 59 & 9 & 83 & 16 & 78 \\
\hline 2 & 91 & 10 & 70 & 17 & 83 \\
\hline 3 & 96 & 11 & 48 & 18 & 63 \\
\hline 4 & 80 & 12 & 72 & 19 & 76 \\
\hline 5 & 78 & 13 & 83 & 20 & 61 \\
\hline 6 & 78 & 14 & 46 & 21 & 46 \\
\hline 7 & 83 & 15 & 61 & 22 & 59 \\
\hline 8 & 61 & & & & \\
\hline
\end{tabular}

The average of the students' scores is 70.68. Although the average is not quite promising, the highest score among the students is 96. Besides, it can be seen from the scores that only a small number of the students scored lower than 60 . It is likely that those having low scores are not the kinesthetic type of learners since according to Barr (2016), kinesthetic learners can benefit from Quizlet when it comes to testing. Nevertheless, Quizlet has been proven out to be the aid for teachers to overcome students' low participation and lack of attention. Furthermore, students' engagement and persistence in learning are also apparent during the lessons, supported by the interview data. 
Students' responses to the implementation of quizlet

This section describes how students responded to the use of Quizlet in the classroom. The result shows that students realized the positive effect of using Quizlet in learning vocabularies. The students assumed that Quizlet provided enjoyable learning, generated their autonomy, increased their persistence and engagement in the learning process.

\section{Providing enjoyable learning}

The finding from the interview demonstrated that Quizlet provides enjoyable learning for students. Some students stated that they enjoyed learning vocabularies due to various features on the application. Those different features gave 'fun experience' for students to feel 'different way' of learning.

Some students further declared that they rarely got bored in the learning process because they did various activities through Quizlet. They could easily do drilling from Learn, Flashcards, and Match to memorize new vocabularies. They could check the pronunciation and spelling of each vocabulary in Spell and practice writing on Write feature as well. "Learning vocabularies became more fun", the students said. They also said that they felt like playing and learning at the same time. It can be seen in this statement:

“....Quizlet makes my learning more fun. I like the features of the apps. It made me enjoy learning new vocabularies and decreased my boredom" (Student 1).

This statement is also confirmed by the observation findings showing that most of the students enthusiastically tried the different type of Quizlet features during the learning process. It also emphasizes that various types of features are able to give students 'richer ways' to engage with Quizlet (Ravipati, 2017). It also proves that Quizlet is a new, enjoyable way of vocabulary learning (Lander, 2016; Beyer \& Lynch, n.d.);

\section{Generating learner autonomy}

Furthermore, the use of Quizlet in the classroom helped students generate their autonomy. Since Quizlet is easily accessed, they could use the apps inside and outside the classroom. The ease of access improved students' chances to learn independently. The finding shows that most of the students voluntarily learned vocabularies using Quizlet. Students' autonomy revealed in the following statement:

"I often used Quizlet when I was at home since this application could be accessed on my smartphone. Hence, I can decide when I should learn and what (material) that I wanted to repeat" (Student 2).

This statement indicates that students' autonomy had been developed. It is in line with the observation finding in meeting 2 that demonstrated students' initiation to select their own choice to learn vocabularies. It is also relevant to Nation (2001) who mentioned that autonomous learners are capable of taking control of their own learning.

Another autonomy is shown from students' ability in controlling their progress by checking their score in Score feature. Student 3 mentioned that she could know her ability by observing the score progress. She could also know what vocabularies that she had not known yet. Hence, this response is related to Kálecký (2016) who claimed that through Quizlet, students are able to control their progress and directly see at which part of vocabulary sets the students to lack.

\section{Generating learner persistence}

Another merit exposed to students' response is that the use of Quizlet improved their persistence in learning vocabularies. All interviewed students agreed that they tried their best to memorize vocabularies appeared on Quizlet in order to reach the best score. The desire to reach the top preserved their persistence in facing some challenges during the learning process.

Furthermore, Student 3 said that Quizlet helped her lengthen the attention span. She further explained that she had to keep practicing in Quizlet and fully pay attention to the lecturer's instruction, hence she was able to defeat her friends' score. In other words, the feeling of competition motivated students to keep their persistence. It is in line with Lens, Lacante, and Vansteenkiste (2005) who declared that the persistence did not only depend on their motivation but also the competing activity. 
This finding demonstrates that the implementation of Quizlet was quite successful in turning students' short attention span into persistence in the learning. Hence this statement confirms the finding of the observation in meeting 3 .

\section{Generating learner engagement}

The last finding from the interview is the improvement in students' engagement. The students assumed that they tended to be more active in the classroom. Since all students were ordered to use Quizlet in the classroom, they automatically participated in classroom activity, as mentioned by Student 4 who said that:

"Firstly I felt 'obliged' to access Quizlet but after I tried it, I became more motivated to use it again and again. I also wanted to be more active in class because I learned a lot of vocabularies) from it (Quizlet)" (Student 4).

This report designates that the use of Quizlet encouraged the students to be more engaged in each classroom activity. Despite some students claimed that using Quizlet as a perfect order, but in the end, they used it inside and even outside the classroom as voluntary. This finding emphasizes that learners' engagement in the classroom is apparent (Vargas, 2011; Barr, 2016; Beyer \& Lynch, n.d.).

Additionally, the finding also shows that some students got engaged to Quizlet due to their curiosity. When they failed to get 100, they tried to play again, fixed the mistakes, and memorized the difficult vocabularies. "As long as I had not succeeded in reaching 100, I was curious and trying to play again and again", said Student 1. Its statement is relevant to Laricchia (2013) who assumed that "engagement is all about being genuinely curious and actively exploring whatever has caught your interest".

\section{CONCLUSION}

As it was observed, the merits of Quizlet are concerned with the provision of enjoyable learning, generating leaner autonomy, persistence, focus, and attention, as well as engagement. The students did not get bored easily, as they could focus on the vocabulary set the whole meeting by exploring what is needed by them and the way of learning they prefer. Short attention span and low focus are changed into persistence and engagement in the learning. Furthermore, learner autonomy is reflected in continual learning outside the class as the students are motivated to get their names shown at the top scorer lists. However, further studies are required to see its significance, whether or not Quizlet can improve students' motivation and achievement. Robust research procedures are also suggested for the improvement of this study.

\section{ACKNOWLEDGMENT}

We would like to extend our sincerest gratitude to the English Education Study Program of Suryakancana University that has always been supportive so that this study could be done, and also to the fourth year students of English Education Department who participated in this study.

\section{REFERENCES}

Andarab, M. S. (2017). The effect of using quizlet flashcards on learning English vocabulary. Proceedings of 113th The IIER International Conference (p. 37). Frankfurt, Germany.

Ashcroft, R. J., \& Imrie, A. C. (2014). Learning vocabulary with digital flashcards. JALT2013 Conference Proceedings (pp. 639-646). Tokyo: JALT.

Barr, B. W. B. (2016). Checking the effectiveness of quizlet as a tool for vocabulary learning. The Center of EFL Journal, 1(2), 36-48. https://doi.org/10.15045/ELF_0020104.

Beyer, L. M., \& Lynch, K. N. (n.d.). Flashcards versus quizlet: Achieving maximal verbosity.

Gass, S. M., \& Selinker, L. (2008). Second language acquisition: An introductory course ( $3^{\text {rd }}$ ed.). New York: Routledge.

Groot, P. J. M. (2000). Computer assisted second language vocabulary acquisition. Language Learning \& Technology, 4(1), 56-76.

Groot, A. M. B. De, \& Keijzer, R. (2000). What is hard to learn is easy to forget: The roles of word concreteness, cognate status, and word frequency in foreign-language vocabulary learning and forgetting. Language Learning, 50(1), 1-56.

Kálecký, R. (2016). Quizlet vs. vocabulary notebook: The impact of different methods of storing and revising vocabulary on students' progress, retention, and autonomy. Masaryk University.

Kose, T., Cimen, E., \& Mede, E. (2016). Perceptions of EFL learners about using an online tool for vocabulary learning in EL classrooms: A pilot project in Turkey. Procedia - Social and 
Behavioral Sciences, 232, 362-372. https://doi.org/10.1016/j.sbspro.2016.10.051.

Lander, B. (2016). Quizlet: What the students think - a qualitative data analysis. In $\mathrm{S}$. PapadimaSophocleous, L. Bradley, \& S. Thouësny (Eds.), CALL communities and culture - short papers from EUROCALL 2016 (pp. 254-259). Researchpublishing.net.

https://doi.org/https://doi.org/10.14705/rpnet.2016 .eurocall2016.571.

Laricchia, P. (2013). Curious and engaged. Retrieved from http://livingjoyfully.ca/articles/curious-andengaged/.

Lens, Lacante, and Vansteenkiste (2005). Study Persistence and Academic Achievement as a Function of the Type of Competing Tendencies. European Journal of Psychology of Education., 3, 275-287.

Nation, I. S. P. (2001). Learning vocabulary in another language. Cambridge: Cambridge University Press.

Nation, I. S. P., \& Macalister, J. (2010). Language curriculum design.

Puentedura, R. R. (2006). Transformation, technology, and education.
Puentedura, R. R. (2010). SAMR and TPCK: Intro to advanced practice.

Ravipati, S. (2017). New quizlet feature lets students customize study materials with pictures. Retrieved from

https://thejournal.com/articles/2017/08/24/newquizlet-feature-lets-students-customize-studymaterials-with-pictures.aspx.

Romrell, D., Kidder, L. C., \& Wood, E. (2014). The SAMR model as a framework for evaluating mlearning, 1-15.

Schmidt, N. (2008). Instructed second language vocabulary learning. Language Teaching Research, 12(3), 329-363.

Steinberg, D. D., \& Sciarini, N. V. (2006). An introduction to psycholinguistics.

Vargas, J. M. (2011). Modern learning: Quizlet in the social studies classroom. Wichita State University.

Wieking, B. A. (2016). Technology integration and student learning motivation. Northwestern College, Orange City, IA. Retrieved from http://nwcommons.nwciowa.edu/education_maste $\mathrm{rs} / 5 /$. 